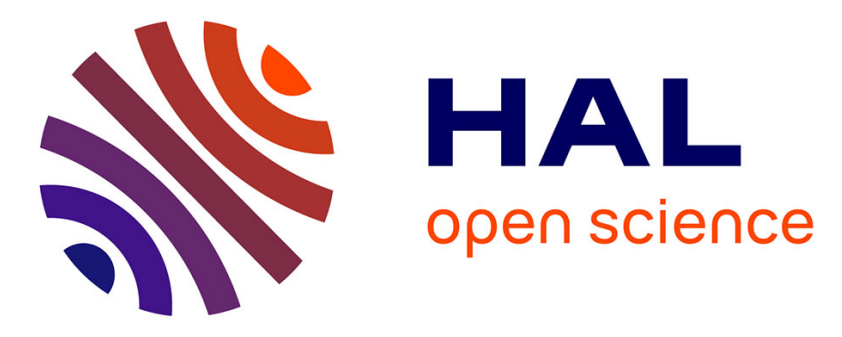

\title{
Host populations' perceptions toward migrants: The effect of private/public settings and the moderating role of threat
}

Christelle Maisonneuve, Benoît Testé, Anne Taillandier-Schmitt, Michael

Dambrun

\section{To cite this version:}

Christelle Maisonneuve, Benoît Testé, Anne Taillandier-Schmitt, Michael Dambrun. Host populations' perceptions toward migrants: The effect of private/public settings and the moderating role of threat. International Journal of Intercultural Relations, 2014, 41, pp.45 - 56. 10.1016/j.ijintrel.2014.05.006 . hal-01723290

\section{HAL Id: hal-01723290 \\ https://hal.univ-rennes2.fr/hal-01723290}

Submitted on 6 Mar 2018

HAL is a multi-disciplinary open access archive for the deposit and dissemination of scientific research documents, whether they are published or not. The documents may come from teaching and research institutions in France or abroad, or from public or private research centers.
L'archive ouverte pluridisciplinaire HAL, est destinée au dépôt et à la diffusion de documents scientifiques de niveau recherche, publiés ou non, émanant des établissements d'enseignement et de recherche français ou étrangers, des laboratoires publics ou privés. 


\title{
Host populations' perceptions toward migrants: The effect of private/public settings and the moderating role of threat
}

\author{
Christelle Maisonneuve ${ }^{\mathrm{a}, *}$, Benoit Testé ${ }^{\mathrm{a}, 1}$, Anne Taillandier-Schmitt $^{\mathrm{b}}$, \\ Michael Dambrun ${ }^{\mathrm{c}}$ \\ a LAUREPS (CRPCC, EA 1285), University of Rennes 2, Place du recteur Henri le Moal, CS 24307, 35043 Rennes Cedex, France \\ b EA2114 (Psychologie des Ages de la Vie), Université François Rabelais de Tours, 3 rue des Tanneurs, 37000 Tours, France \\ c LAPSCO/UMR 6024, Université Blaise Pascal, Clermont Fd II, 34 avenue Carnot, 63037 Clermont-Fd Cedex, France
}

\section{A R T I C L E I N F O}

\section{Article history:}

Received 2 April 2013

Received in revised form 26 April 2014

Accepted 30 May 2014

\section{Keywords:}

Acculturation

Host community

Public/private contexts

Threat

\begin{abstract}
A B S T R A C T
In the light of the French integration model, the present research was designed to examine the influence of host culture adoption and original culture conservation in the private sphere and the public sphere on the host population's judgments of migrants. Using the scenario method, in a pilot and a main studies $(n=156)$ migrants' targets were portrayed as adopting the host culture or conserving the original one, depending on the private (at home) or public (at work) setting. Our results suggest that the host population's perceptions are influenced by the behaviors adopted by migrants in both the private and public spheres, and by the type of judgment being made, as the effects we found differed according to the dependent variable being examined (affective, normative, and perception of integration into French society). Finally, the main study reveals that threat significantly moderates host populations' perceptions. Three main contributions and one implication are discussed and perspectives for future researches are proposed.
\end{abstract}

(c) 2014 Elsevier Ltd. All rights reserved.

\section{Introduction}

Acculturation models based on Berry's research (1980) define acculturation in terms of two orthogonal dimensions conservation of the original culture and frequency of contact with the host population. In their model, Bourhis, Moise, Perrault, and Senecal (1997) substituted adoption of the host culture for frequency of contact with the host population. Such bi-dimensional models have been widely used to analyze migrants' strategies (Barrette, Bourhis, Personnaz, \& Personnaz, 2004; Berry, 1980, 2005; Bourhis \& Bougie, 1998) and to explore how host communities perceive migrants (Berry, 2006; Berry \& Kalin, 1995; Berry, Kalin, \& Taylor, 1977; Bourhis \& Bougie, 1998). Berry and Bourhis et al.'s models cross the two dimensions of acculturation to define four possible orientations for migrants and host populations. The dimensions for hosts are referred to as integration (when the host population expects migrants to both conserve their original culture and adopt the host culture), assimilation (when the host population expects migrants to adopt the host culture without conserving their original culture), segregation (when the host population expects migrants to conserve only their original culture),

\footnotetext{
* Corresponding author at: Département Carrières Sociales, 263 av du général Leclerc, CS44202, 35042 Rennes Cedex, France. Tel.: +33 02 23 23 4253 ; fax: +330223234091.

E-mail addresses: christelle.maisonneuve@univ-rennes1.fr (C. Maisonneuve), benoit.teste@univ-rennes2.fr (B. Testé), anne.taillandier@univ-tours.fr (A. Taillandier-Schmitt), michael.dambrun@univ-bpclermont.fr (M. Dambrun).

1 Tel.: +330299141955.
} 
and exclusion (when the host population expects migrants to neither conserve their original culture nor adopt the host culture). This model is useful for situating the orientations of host countries on both the individual and political levels. For example, on the political level, Canada's multiculturalism approach corresponds to integration (Bourhis \& Bougie, 1998), whereas America's melting pot approach corresponds to assimilation (Bourhis \& Bougie, 1998; Van Oudenhoven, Ward, \& Masgoret, 2006). France's integration model is usually defined as assimilationist (Barrette et al., 2004; Sabatier \& Berry, 1994); however, the situation is more complex than this because, despite a clear injunction to assimilate, maintenance of the original culture is tolerated when it occurs in the private sphere. The first aim of our research was to show that the type of acculturation strategy (adoption of host culture vs. conservation of original culture) that migrants adopt in the private and public spheres influences the host population's evaluations of those migrants. We addressed this issue through two studies in which participants were asked to evaluate targets who differed according to whether they conserved their original culture or adopted the host culture in private and in public (Navas et al., 2005). We used the scenario method (Van Oudenhoven, Prins, \& Buunk, 1998) to portray the targets' behaviors in private vs. public settings. The second aim of our research was to show that the level of perceived threat the host population associates with the presence of migrants moderates the relation between acculturative preference and private vs. public behaviors.

\subsection{Strategies adopted by migrants and the French integration model}

In the literature, France's "republican integration model" of acculturation is classically considered to be assimilationist (Barrette et al., 2004; Sabatier \& Berry, 1994). For example, Sabatier and Boutry (2006), referring to Bolzman (2001), define France as a "typical example of assimilationist citizenship", corresponding to a Universalist ideology in which differences tend to be ignored and equal treatment for all individuals is promoted. Under this conception, immigrants are expected to adopt French culture, and to accept and respect France's republican principles. Consequently, and as Guimond (2010) pointed out, the epithet "integration" in the model's name is misleading. However, closer examination of the French integration ideal shows that it is more complex than simple assimilation. According to Kamiejski, Guimond, De Oliveira, Er-Rafiy, and Brauer (2012), the French model is framed by the orthogonal dimensions of citizenship and secularism. Their work was based on the French constitution of 1958, which states "France is an indivisible, secular, democratic, and social republic". ${ }^{1}$. The citizenship dimension corresponds to the principle of indivisibility ("French society is composed of citizens rather than communities" - item created by Kamiejski et al. to define the citizenship dimension), whereas the secularism dimension corresponds to "a political concept involving the separation of civil society and religious society in which the State has no religious power and Churches have no political power" 2 (Capitant, quoted by Barbier, 1995, p.8). In daily life, France's integration model distinguishes between the public and private spheres, with people being free to choose their way of life and how they express their religious beliefs in private (Sabatier \& Boutry, 2006); however, prominent displays of religious or sectarian symbols in government-run institutions are prohibited. Navas, Rojas, Garcia, and Pumares (2007) observed that classic definitions of acculturation orientations are not really adapted to the complex realities of modern societies containing different spheres of life. Navas et al. (2007) differentiated between peripheral domains (work, economics, politics) and more central domains (family, religion, way of thinking). They suggested, as did Brown and Zagefka (2011), that migrants adapt their behaviors to the context, and that a host population's judgments of migrants depend on the strategies migrants adopt in different contexts. Arends-Tóth and Van de Vijver (2003) proposed this perspective when they compared the acculturative preferences in the private and public spheres of Dutch and Turkish-Dutch people. They found that Dutch people prefer migrants to assimilate in both the private and public spheres but that Turkish-Dutch people tend to choose integration in the public sphere and separation in the private sphere.

The present research focused on the situation in France, where the "French integration model" is strongly ingrained, both socially and politically. We examined whether or not it guide participants' judgments of migrants' acculturation strategies. We expected the host population's judgments of migrants to depend on the acculturation strategies those migrants adopt in the public and private spheres. We investigated this by asking participants to judge a migrant target on the basis of the acculturation strategies (adoption of host culture or conservation of original culture) adopted in a private setting and a public setting. According to the French integration model, the host population's judgments should be influenced more strongly by migrants' behaviors in public than by their behaviors in private. However, these judgments may be moderated by the degree to which participants perceive themselves threatened by the presence of migrants.

\subsection{Threat as a moderator}

Threat is considered a central variable in explaining prejudices and negative attitudes toward migrants (Bourhis \& Bougie, 1998; Florack, Piontkowski, Rohmann, Balzer, \& Perzig, 2003; Stephan \& Stephan, 1996; Stephan, Renfro, Esses, Stephan, \& Martin, 2005). Moreover, threat is also linked with the host populations' acculturative preferences (Tip et al., 2012; Van Acker \& Vanbeselaere, 2011). Lỏpez-Rodríguez, Zagefka, Navas, and Cuadrado (2014) tested a model with threat as a

\footnotetext{
1 “la France est une république indivisible, laïque, démocratique et sociale".

2 “une conception politique impliquant la séparation de la société civile et de la société religieuse, l'Etat n’exerçant aucun pouvoir religieux et les Eglises aucun pouvoir politique".
} 
mediator between perceived stereotypes and host acculturative preferences. They found that perceived threat is positively correlated with preference for adoption and negatively correlated with preference for conservation. Similarly, Florack et al. (2003) reported that the wish to see migrants excluded or segregated (kept at a distance) is stronger among people who feel threatened by the presence of migrants than it is among people who feel enriched by their presence. In addition, people who feel threatened by the presence of migrants have a stronger preference for assimilation (adoption of the host culture and non-conservation of the original culture), whereas people who feel enriched by the presence of migrants have a stronger preference for integration.

Nevertheless, the effect of perceived threat on a host population's attitudes to migrants and acculturation preferences seems to be sensitive to the "origin of the target" variable, with perceived threat being stronger when the targeted migrant group is devalued (Lỏpez-Rodríguez et al., 2014; Montreuil \& Bourhis, 2001). The target used in our research (described in the scenario) was from North Africa. Because our objective was not to compare the threat perceived by the host population with respect to different target groups, we used a single target origin, chosen in the light of the situation in France. In fact, North Africa has been one of the largest sources of migrants to France in recent years, especially from the 1970s until the 1990s (Tribalat, 2010), and it is always the North African community that the French media and politicians focus on when problems linked to immigration occur (Sorel-Sutter, 2011). Furthermore, although migrants from regions such as Eastern Europe are also seen as threatening in France, migrants from North Africa and their descendants are always singled out (Spire, 1999), frequently criticized, devalued rather than valued (Barrette et al., 2004), and perceived as threatening (Dambrun \& Guimond, 2001). Indirect proof of this is provided by the fact that people of North African origin often suffer from prejudice and discrimination (Amadieu, 2008).

\subsection{Overview}

According to Navas et al. (2007), a host population's perceptions of migrants will depend on the acculturation strategies those migrants adopt in the public and private spheres. Our research's first aim was to test this assertion. We did this through a pilot study and a main study, both based on the scenario method (Van Oudenhoven et al., 1998), in which we described migrant targets in terms of the acculturation strategies they adopt in the public (at work) and private (at home) spheres. Some of the targets adopted the same strategy in public and in private; other targets adopted different strategies in the two spheres. In both the pilot study and the main study we evaluated participants' affective preferences, normative prescriptions, and perceptions of target integration by asking each participant to answer questions about just one target. The pilot study included control measures for perceptions of target coherence and the social credibility of the situation described by the target. In order to explore how perceived threat moderates participants' perceptions of the target as a function of the strategies adopted in the two spheres, in the main study we added measures of perceived threat to the pilot study's central dependent variables (affective, normative, perception of integration).

The pilot study allowed us to test our initial hypotheses, which we also tested in the main study. Because France's integration model is deeply ingrained into society, we expected participants' assessments of the targets to be influenced more strongly by the targets' public strategies than by their private strategies. Hence, we postulated that adoption of the host culture in the public sphere would be evaluated positively whatever the behavior adopted in private. Consequently, participants were expected to judge targets who adopt the host culture in public to be likeable, to be models of what is expected (prescriptive norm), and to be more integrated into French society than targets who conserve their original culture in public (H1a). We also expected to find an interaction between "strategy at work" (adoption vs. conservation) and "strategy at home" (adoption vs. conservation). For targets who conserve their original culture in public, we expected participants to prefer those who adopt the host culture in private to those who conserve their original culture in both spheres (H1b).

Concerning the threat effect, we expected perceived threat to moderate the link between participants' acculturative preferences and the targets' strategies in public and in private, with high levels of perceived threat leading participants to disapprove of targets who conserve their original culture and approve of migrants who adopt the host culture at work (H2a) and at home (H2b). We expected this effect to be stronger in the public sphere than in the private sphere, because the French integration model is more "permissive" with respect to the private sphere than with respect to the public sphere (H2c).

\section{Pilot study}

\subsection{Method}

\subsubsection{Participants}

Participants were 24 men and 17 women (mean age $=31.17, S D=7.62$ ), all of who were employees taking life-long learning courses at the University of Rennes or the University of Tours, in France. They were recruited during their classes and were free to refuse to participate. Those who agreed to participate completed a questionnaire presented as being about perceptions of migrants.

\subsubsection{Procedure and design}

We prepared four different scenarios (translated from Van Oudenhoven et al., 1998, and adapted from Maisonneuve \& Testé, 2007) describing a target called Ahmed, who is from North Africa and who displayed one of four acculturation 
Table 1

Presentation of experimental conditions.

\begin{tabular}{lll}
\hline & Strategy at home & Conservation \\
\cline { 2 - 3 } & Adoption & Public assimilationist \\
$\begin{array}{l}\text { Strategy at work } \\
\text { Adoption } \\
\text { Conservation }\end{array}$ & Assimilationist & Separationist \\
\hline
\end{tabular}

strategies: (1) adoption of the host culture "at home" and "at work" (assimilationist target); (2) conservation of his original culture in both settings (separationist target); (3) adoption of the host culture "at home" and conservation of his original culture "at work" (public-separationist target); (4) adoption of the host culture "at work" and conservation of his original culture "at home" (public-assimilationist target ${ }^{3}$ ). Depending on the experimental condition, each participant was presented with one of the four scenarios; therefore each participant evaluated just one target.

The experimental design (see Table 1 ) was 2 (strategy at home: adoption vs. conservation) $\times 2$ (strategy at work: adoption vs. conservation).

\subsubsection{Measures}

All the items were evaluated on 7-point Likert scales, from 1 "not at all" to 7 "totally".

Affective measures. Participants gave their opinions on two items: "Do you find the main character in this story likeable?" and "Do you think you would get along with this person?" (inspired by Van Oudenhoven et al., 1998). As the correlation between the two items was positive, $r=.62, p=.010$, we averaged them into a single "affective mean".

Prescriptive norm measure. Participants gave their opinions on a single item: "Do you think all members of this community should behave like the main character in this story?" (Van Oudenhoven et al., 1998, p. 1008).

Perceived integration of the target into French society. Participants gave their opinions on a single item measuring the character's integration into French society ${ }^{4}$ : "In your opinion, how well integrated into French society does Ahmed appear to be?" (from Testé, Maisonneuve, Assilamehou, \& Perrin, 2012).

Perception of acculturation strategies. Participants responded to two items designed to check that the manipulation of the scenarios had functioned as intended: "In your opinion, does the character in this story want to keep his original culture?" and "In your opinion, does the character in this story want to adopt the host culture?" The correlation obtained $(r=-.61$, $p<.001$ ) suggests that the two dimensions are not orthogonal.

Perceived consistency of the target. Participants responded to two control items designed to examine whether the target's behavior was perceived as consistent: "In your opinion, is Ahmed's behavior consistent?" and "Is Ahmed's behavior contradictory?" (reversed). These items are positively correlated, $r=.46, p=.003$, which allowed us to calculate a "perceived target consistency" score.

Social credibility of the situation described by the target. Four items were used to control the participants' perceptions of the social credibility of the situation described: "Do you think the situation described here is real?", "Is this type of situation frequently encountered in real life?", "Is it a credible situation?", and "Did you find the situation presented surprising?" (reversed). All items were correlated with each other (from $r=.39$ to $r=.69$ ) and reliability was good, (Cronbach's alpha $=.84$ ), which allowed us to calculate a "social credibility of the situation described by the target" score.

\subsection{Results and discussion}

All the analyses were carried out as 2 (strategy at home: adoption vs. conservation) $\times 2$ (strategy at work: adoption vs. conservation) ANOVAs. Means and standard deviations of main effects are presented in the text and means and standard deviations of interaction effects are given in Table 2.

\subsubsection{Manipulation check}

2.2.1.1. Perceptions of the target on the conservation dimension. The ANOVA for perceptions of conservation of the original culture revealed a main effect of "strategy at home", $F(1,37)=66.93, p<.001, \eta^{2}=.62$, with targets who conserved their original culture at home being perceived as more strongly conserving their culture $(M=6.65, S D=0.67)$ than targets who adopted the host culture at home $(M=3.14, S D=2.10)$. We also found a main effect of "strategy at work", $F(1,37)=10.93$, $p<.001, \eta^{2}=.21$, with targets who conserved their original culture at work being perceived as more strongly conserving their culture $(M=5.66, S D=1.71)$ than targets who adopted the host culture at work $(M=4.00, S D=2.67)$. These two main effects suggest that our scenarios were perceived in the way intended. We also found an interaction effect, $F(1,37)=5.83, p=.020$,

\footnotetext{
3 "Each mixed target can be named in two ways. We chose "public-separationist" (rather than "private assimilationist") and "public assimilationist" (rather than "private separationist") because of the way we formulated our hypotheses, which present the public sphere as being more decisive than the private sphere in determining perceptions of acculturation preferences."

${ }^{4}$ The term "integration" is used here in its everyday sense to refer to the target's ability to adapt to the host society.
} 
Means (standard deviations) of measures as a function of cultural conservation vs. adoption at home and cultural conservation vs. adoption at work (pilot study).

\begin{tabular}{|c|c|c|c|c|}
\hline & \multicolumn{2}{|l|}{ Conservation at home } & \multicolumn{2}{|l|}{ Adoption at home } \\
\hline & Conservation at work & Adoption at work & Conservation at work & Adoption at work \\
\hline Cultural conservation & $6.82(0.40)$ & $6.44(0.88)$ & $4.40(1.71)$ & $2.00(1.79)$ \\
\hline Cultural adoption & $2.00(1.18)$ & $5.33(1.32)$ & $5.20(1.47)$ & $6.63(0.92)$ \\
\hline Consistency & $5.36(1.30)$ & $3.43(1.69)$ & $2.90(1.37)$ & $4.95(1.94)$ \\
\hline Credibility & $3.75(1.65)$ & $5.41(1.15)$ & $5.20(0.84)$ & $2.90(1.34)$ \\
\hline Affective measure & $3.27(1.63)$ & $4.94(0.77)$ & $4.65(1.13)$ & $3.41(1.26)$ \\
\hline Prescriptive norm & $1.45(0.69)$ & $3.44(1.50)$ & $2.40(1.35)$ & $1.36(0.67)$ \\
\hline Integration into French society & $2.27(1.10)$ & $5.22(1.09)$ & $4.91(1.91)$ & $4.01(0.89)$ \\
\hline
\end{tabular}

Note 1: Conservation at home plus conservation at work corresponds to the separationist target; conservation at home plus adoption at work corresponds to the public-assimilationist target; adoption at home plus conservation at work corresponds to the public-separationist target; adoption at home plus adoption at work corresponds to the assimilationist target.

Note 2: All interactions' effects mentioned in the table are significant and presented in the text.

$\eta^{2}=.13$. Contrast analyses showed that the public-assimilationist target was perceived as conserving his original culture more than the assimilationist target, $F(1,37)=54.60, p<.001, \eta^{2}=.6$; however, the public-assimilationist target was not perceived as conserving his original culture less than the separationist target, $F(1,37)=0.38, p=.538$. The public-separationist target was perceived as conserving his original culture more than the assimilationist target, $F(1,37)=16.85, p<.001, \eta^{2}=.31$, and less than the separationist target, $F(1,37)=17.10, p<.001, \eta^{2}=.32$.

2.2.1.2. Perceptions of the target on the adoption dimension. The ANOVA for perceptions of adoption of the host culture showed a main effect of "strategy at home", $F(1,37)=34.01, p<001, \eta^{2}=.48$, with targets who adopted the host culture at home being perceived as adopting the host culture more strongly $(M=5.95, S D=1.39)$ than targets who conserved their own culture at home $(M=3.50, S D=2.09)$. We also noted a main effect of "strategy at work", $F(1,37)=38.15, p<001, \eta^{2}=.51$, with targets who adopted the host culture at work being perceived as adopting the host culture more strongly $(M=6.05, S D=1.27)$ than targets who conserved their own culture at work $(M=3.52, S D=2.08)$. These two main effects suggest that our scenarios were perceived in the way intended. We also obtained an interaction effect, $F(1,37)=6.03, p=.020, \eta^{2}=.14$. Contrast analyses showed that the public-assimilationist target was perceived as adopting the host culture less than the assimilationist target, $F(1,37)=5.54, p=.024, \eta^{2}=.13$, and more than separationist target, $F(1,37)=36.24, p<.001, \eta^{2}=.49$. We obtained a similar result for the public-separationist target, $F(1,37)=7.12, p=.011, \eta^{2}=.16$, and $F(1,37)=35.35, p<.001, \eta^{2}=.49$.

The main effects show that the participants perceived the strategies described in the scenarios in the way intended. Contrast analyses show first that although the public-assimilationist target was perceived as conserving his own culture less than the assimilationist target, he was not perceived as conserving his own culture less than the separationist target. Second, public-separationist target was perceived differently from single strategies on the adoption dimension. This result suggests that what happens at home weighs more heavily on judgments of whether or not migrants conserve their original culture.

\subsubsection{Control variables}

2.2.2.1. Perceived consistency of the target. The ANOVA revealed only an interaction effect, $F(1,36)=15.26, p<.001, \eta^{2}=.28$, showing that the public-assimilationist and public-separationist targets were perceived as less consistent and more contradictory than, respectively, the assimilationist target, $F(1,36)=4.17, p=.048, \eta^{2}=.01 ; F(1,36)=8.66, p=.005, \eta^{2}=.19$, and the separationist target, $F(1,36)=6.73, p=.013, \eta^{2}=.16 ; F(1,36)=12.45, p<.001, \eta^{2}=.26$.

2.2.2.2. Social credibility of the situation described by the target. The ANOVA revealed only an interaction effect, $F(1,36)=22.60$, $p<001, \eta^{2}=.37$, with both mixed-strategy targets being judged more credible than the two single-strategy targets. Contrast analyses showed that the public-assimilation and public-separation targets were perceived as more credible than, respectively, the assimilationist target, $F(1,36)=17.04, p<.001, \eta^{2}=.32 ; F(1,36)=16.22, p<.001, \eta^{2}=.31$, and the separationist target $F(1,36)=6.50, p=.015, \eta^{2}=.15 ; F(1,36)=7.50, p=.009, \eta^{2}=.17$.

These control measures allowed us to verify that the new scenarios describing the mixed targets were perceived as socially credible, that is, as describing a migrant or a person from a migrant background living in French society. We also checked that the mixed targets who adopted contradictory behaviors in different situations were perceived as mixed targets.

\subsubsection{Affective measure}

The ANOVA revealed only an interaction effect, $F(1,37)=13.58, p=.001, \eta^{2}=.25$, suggesting that participants appreciated the mixed-strategy targets more than the other two targets. Contrast analyses showed that the public-assimilationist and public-separationist targets were appreciated more than, respectively, the assimilationist target, $F(1,37)=7.34, p=.010$, $\eta^{2}=.17 ; F(1,37)=5.07, p=.030, \eta^{2}=.12$, and the separationist target, $F(1,37)=8.70, p=.005, \eta^{2}=.19 ; F(1,37)=6.25, p=.017$, $\eta^{2}=.14$. On the one hand, this result partly supports H1b because we found a preference for the targets who adopted 
mixed strategies compared with the separationist target. On the other hand, we did not find the expected preference of host populations for adoption in the public sphere (main effect expected by H1a) and we did not replicate the previously reported preference for assimilation compared with separation (Maisonneuve \& Testé, 2007; Van Oudenhoven et al., 1998).

\subsubsection{Prescriptive norm}

The ANOVA revealed only an interaction effect, $F(1,37)=19.65, p<.001, \eta^{2}=.32$, indicating that migrants are expected to follow a mixed strategy, ahead of the non-mixed strategies. Contrast analyses showed that the prescriptive norm was stronger for the public-assimilationist and public-separationist strategies than it was for, respectively, the assimilationist strategies, $F(1,37)=18.06, p<.001, \eta^{2}=.33 ; F(1,37)=4.74, p=.036, \eta^{2}=.11$, and the separationist strategies, $F(1,37)=16.52$, $p<.001, \eta^{2}=.31 ; F(1,37)=3.94, p=.054, \eta^{2}=.10$. Thus, the results for this DV do not support H1a and only partly support H1b.

\subsubsection{Integration into French society}

The ANOVA revealed a main effect of "strategy at work", $F(1,37)=6.32, p=.02, \eta^{2}=.13$, suggesting that targets who adopted the host culture at work were perceived as being better integrated $(M=4.55, S D=1.14)$ than targets who conserved their original culture at work $(M=3.52, S D=2.02)$. The ANOVA also revealed an interaction, $F(1,37)=22.28, p=.002, \eta^{2}=.35$, showing that the separationist target was the only target participants considered not to be integrated into French society. The other three targets were considered well integrated into French society. Contrast analyses showed that the separationist target was considered as less-well integrated than the public-assimilationist target, $F(1,37)=25.43, p<.001, \eta^{2}=.41$, and public-separationist target, $F(1,37)=21.36, p<.001, \eta^{2}=.37$. The assimilated target was considered less-well integrated than the public-assimilationist target, $F(1,37)=4.37, p=.043, \eta^{2}=.11$, and as well integrated as the public-separationist target, $F(1,37)=2.50, p=.121$. This result suggests that the separationist target was the only one not to be considered integrated into French society. Our results for this DV support both H1a and H1b.

These findings led us to carry out a larger study in order to replicate our results with a larger sample and to test the moderating effect of perceived threat on participants' judgments.

\section{Main study}

\subsection{Method}

\subsubsection{Participants}

Participants were 115 employees ( 74 women and $41 \mathrm{men}$ ) following lifelong learning courses at the University of Rennes or the University of Tours. The average age of the participants was 33.88 years $(S D=8.55)$.

\subsubsection{Materials, measures and procedure}

Material, measures and procedures were the same as in the pilot study, ${ }^{5}$ except that we removed the "credibility of the situation" and "consistency of the target" measures, and added two new measures to control the host population's perceptions of the target's honesty and hypocrisy. We felt able to remove the "credibility of the situation" and "consistency of the target" measures because the pilot study clearly demonstrated that the mixed scenarios were considered more credible than the non-mixed scenarios, and that the non-mixed targets were considered more consistent than the mixed-targets. The idea behind the two new items was to evaluate the social perception of the truthfulness of Ahmed's declarations. Using a 7-point Likert scale, participants had to describe the target on two traits: "Indicate how these two traits describe Ahmed. For each trait, circle the number that best matches your opinion, from 1 (does not describe Ahmed at all) to 7 (describes Ahmed very well)". The correlation between perceptions of honesty and hypocrisy was negative $(r=-.56, p<.001)$. We averaged both answers (with the recoded reverse "hypocrisy" item) into a single "honesty score".

We also added a threat measure to assess the level of threat perceived by the participants. Using a 7-point Likert scale, participants had to evaluate the threat migrants from North Africa pose in 14 domains: employment market, working atmosphere, political orientation, housing market, local community, education, children, public security, social wellness, cultural values, religion, social life, food habits, and language (Florack et al., 2003). For example, "Thinking about your local community, do you perceive the presence of North Africa migrants as:" 1 (threatening) to 7 (enriching). Only one factor emerged from the factorial analysis (eigenvalue $=8.88$, variance explained $=63.41 \%$ ), and reliability was good (Cronbach's alpha $=.95)$.

\subsection{Results and discussion}

All the analyses were carried out as 2 (strategy at home: adoption vs. conservation) $\times 2$ (strategy at work: adoption vs. conservation) ANOVAs. Means and standard deviations of main effects are presented in the text and means and standard

\footnotetext{
${ }^{5}$ As in pilot study, correlation between the two items of "affective measure" was positive, $r=.68, p<.001$. We calculated an "affective mean". Correlation between "perception of adoption" and "perception of conservation" was negative, $r=-.58, p<.001$.
} 
Table 3

Means (standard deviations) of measures as a function of conservation vs. adoption of culture at home and conservation vs. adoption of culture at work (main study).

\begin{tabular}{|c|c|c|c|c|}
\hline & \multicolumn{2}{|l|}{ Conservation at home } & \multicolumn{2}{|l|}{ Adoption at home } \\
\hline & Conservation at work & Adoption at work & Conservation at work & Adoption at work \\
\hline Cultural conservation* & $6.65(0.84)$ & $5.70(1.44)$ & $4.55(1.74)$ & $2.18(1.94)$ \\
\hline Cultural adoption* & $1.53(0.86)$ & $4.29(1.42)$ & $5.17(1.28)$ & $6.00(1.33)$ \\
\hline Honesty & $5.86(1.48)$ & $5.18(1.66)$ & $5.46(1.40)$ & $4.04(1.55)$ \\
\hline Affective measure* & $3.70(1.38)$ & $4.82(1.06)$ & $4.70(1.28)$ & $3.78(1.68)$ \\
\hline Prescriptive norm* & $1.61(0.85)$ & $2.69(1.69)$ & $2.83(1.55)$ & $2.11(1.74)$ \\
\hline Integration into French society* & $2.54(1.39)$ & $4.59(1.42)$ & $4.86(1.46)$ & $4.76(1.33)$ \\
\hline
\end{tabular}

Note 1: Conservation at home plus conservation at work corresponds to the separationist target; conservation at home plus adoption at work corresponds to the public-assimilationist target; adoption at home plus conservation at work corresponds to the public-separationist target; adoption at home plus adoption at work corresponds to the assimilationist target.

Note 2: Stars characters indicate which interactions' effects are significant and presented in the text.

deviations of interaction effects are given in Table 3. In order to examine the moderating effect of perceived threat, we carried out a 2 (strategy at home, coded -1 and +1$) \times 2$ (strategy at work, coded -1 and +1$) \times$ threat-enrichment dimension (centered at the mean) factorial regression (Cohen, Cohen, West, \& Aiken, 2003).

\subsubsection{Manipulation check}

3.2.1.1. Perceptions of the target on the conservation dimension. The ANOVA for conservation of original culture revealed a main effect of "strategy at home", $F(1,112)=94.01, p<001, \eta^{2}=.45$, showing that the target who conserved his culture at home was considered to conserve his original culture more strongly $(M=6.11, S D=1.30)$ than the target who adopted the host culture at home $(M=3.41, S D=2.18)$. We also observed a main effect of "strategy at work", $F(1,112)=32.67, p<.001, \eta^{2}=.22$, suggesting that the target who conserved his original culture at work was considered to conserve his original culture more strongly $(M=5.54, S D=1.74)$ than the target who adopted the host culture at work $(M=4.15, S D=2.42)$. Finally, the ANOVA revealed an interaction effect, $F(1,112)=5.98, p=.01, \eta^{2}=.04$. Contrast analyses showed that the public-separationist target was perceived to conserve his original culture less than the separationist target, $F(1,112)=25.11, p<.001, \eta^{2}=.18$, and more than the assimilationist target, $F(1,112)=32.46, p<.001, \eta^{2}=.22$. We obtained similar results for the public-assimilationist target, $F(1,112)=5.79, p=.020, \eta^{2}=.05$ and $F(1,112)=77.32, p<.001, \eta^{2}=.41$, respectively.

3.2.1.2. Perceptions of the target on the adoption dimension. The ANOVA for adoption of the host culture also revealed a main effect of "strategy at home", $F(1,112)=128.95, p<.001, \eta^{2}=.53$, suggesting that the target who adopted the host culture at home was considered to adopt the host culture more strongly $(M=5.57, S D=1.36)$ than the target who conserved his original culture at home $(M=3.10, S D=1.83)$. We also found a main effect of "strategy at work", $F(1,112)=58.06, p<.001, \eta^{2}=.34$, showing that the target who adopted the host culture at work was considered to adopt the host culture more strongly $(M=5.04, S D=1.61)$ than the target who conserved his original culture at work $(M=3.45, S D=2.13)$. Finally, the ANOVA also revealed an interaction effect, $F(1,112)=16.81, \mathrm{p}<.001, \eta^{2}=.13$. Contrast analyses indicated that the public-separationist target was perceived as adopting the host culture less strongly than the assimilationist target, $F(1,112)=6.04, p=.015$, $\eta^{2}=.05$, and more strongly than the separationist target, $F(1,112)=114.13, p<.001, \eta^{2}=.50$. We obtained a similar result for the public-assimilationist target, $F(1,112)=27.61, p<.001, \eta^{2}=.20$, and $F(1,112)=70.53, p<.001, \eta^{2}=.39$, respectively.

The main effects show that the participants perceived the strategies described in the scenarios in the way intended. Interactions showed that mixed strategies are perceived differently from single strategies on the adoption and conservation dimensions.

\subsubsection{Control variables: Perceptions of the target's honesty}

The ANOVA for the target's perceived honesty revealed two main effects. First, targets who conserved their original culture at home $(M=5.48, S D=1.61)$ were perceived as being more honest than targets who adopted the host culture at home $(M=4.80, S D=1.62), F(1,110)=6.80, p=.01, \eta^{2}=.05$. Second, targets who conserved their original culture at work $(M=5.65, S D=1.44)$ were considered more honest than targets who adopted the host culture at work $(M=4.69, S D=1.69)$, $F(1,110)=12.89, p<.001, \eta^{2}=.10$. Hence, participants seemed to accept that migrants conserve part of their original culture and felt that migrants who admit to conserving their original culture are "necessarily" being honest. Conversely, participants considered as dishonest migrants who claimed to adopt the host culture at home, as they believe it is impossible for a migrant to fully adopt the host culture at home.

\subsubsection{Affective measure}

The ANOVA revealed only an interaction effect between "strategy at work" and "strategy at home", $F(1,112)=16.45$, $p<.001, \eta^{2}=.12$, indicating that the public-assimilationist target was considered more likeable than the assimilationist target, $F(1,112)=10.42, p=.001, \eta^{2}=.09$, and the separationist target, $F(1,112)=8.71, p=.003, \eta^{2}=.07$. We obtained similar 
results for the public-separationist target, $F(1,112)=7.77, p=.010, \eta^{2}=.06$, and $F(1,112)=6.38, p=.012, \eta^{2}=.05$. This was not the result we expected (does not support $\mathrm{H} 1 \mathrm{a}$ and only partly supports $\mathrm{H} 1 \mathrm{~b}$ ) but it is consistent with the results of study 1 , as targets who adopted the host culture in both spheres or who conserved their own culture in both spheres were judged less likeable than targets who adapted their strategy according to the situation.

\subsubsection{Prescriptive norm}

The ANOVA revealed only an interaction effect, $F(1,110)=8.84, p=.003, \eta^{2}=.07$. Contrast analyses showed that the prescriptive norm was stronger for the public-assimilationist and public separationist strategies than it was for the separationist strategy, $F(1,110)=6.43, p=.012, \eta^{2}=.06$, and $F(1,110)=7.86, p=.001, \eta^{2}=.07$. However, the strength of the prescriptive norm was similar for the two mixed strategies and the assimilationist strategy: $F(1,110)=1.89, p=.171$ for the publicassimilationist target and $F(1,110)=2.80, p=.097$ for the public-separationist target. As in the pilot study, we did not obtain a main effect; hence, the results do not support H1a. However, the result of the interaction suggests the existence of a prescriptive norm among the host population that leads people to prefer migrants to adopt mixed acculturation strategies, or assimilation rather than separation, as postulated in $\mathrm{H} 1 \mathrm{~b}$.

\subsubsection{Integration into French society}

The ANOVA revealed a main effect of "strategy at work", $F(1,111)=13.80, p<.001 \eta^{2}=.16$, which supports H1a, as participants judged targets who adopted the host culture at work to be more integrated $(M=4.66, S D=1.37)$ than targets who did not adopt the host culture at work $(M=3.76, S D=1.83)$. The main effect of "strategy at home" was also obtained, $F(1$, $111)=22.60, p<.001, \eta^{2}=.10$, suggesting that participants judged targets who adopted the host culture at home to be more integrated $(M=4.82, S D=1.39)$ than targets who did not adopt the host culture at home $(M=3.70, S D=1.73)$.

The ANOVA also revealed an interaction effect, $F(1,111)=16.54, p<.001, \eta^{2}=.12$. Contrast analysis showed that the separationist target was considered less integrated than the public-assimilationist target, $F(1,111)=31.41, p<.001, \eta^{2}=.22$, and than the public-separationist target, $F(1,111)=37.55, p<.001, \eta^{2}=.25$. The assimilationist target was perceived as being as well integrated as the two mixed-strategy targets. The main effect of "strategy at work" support H1a and the interaction effect is in line with H1b and with the results obtained in the pilot study.

\subsubsection{Threat as a moderator}

We expected that the more people felt threatened by the presence of migrants, the more they would approve of targets who adopt the host culture and disapprove of targets who conserve their original culture at work (H2a) and at home (H2b). A 2 (strategy at work, coded -1 and +1 ) $\times 2$ (strategy at home, coded -1 and +1 ) $\times$ threat-enrichment dimension (centered at the mean) factorial regression revealed an interaction effect between "strategy at home" and perceived threat on the affective mean, $F(1,108)=11.35, p=001, \eta^{2}=.09$, indicating that the more participants felt threatened by migrants, the stronger their preference for targets who adopt the host culture "at home" and the stronger their rejection of targets who conserve their own culture "at home".

The factorial regression also revealed an interaction between "strategies at work" and "perceived threat", $F(1,108)=6.88$, $p=009, \eta^{2}=.05$, suggesting that the more people feel threatened by the presence of migrants, the stronger their preference for migrants who adopt the host culture at work and the stronger their rejection of migrants who conserve their own culture at work. These results support hypotheses $\mathrm{H} 2 \mathrm{a}$ and $\mathrm{H} 2 \mathrm{~b}$. Hypothesis $\mathrm{H} 2 \mathrm{c}$ was that the effect of threat on perceptions of migrants' acculturation strategies will be stronger in the public sphere than in the, more permissive, private sphere. None of the interaction effects between "strategy at home", "strategy at work", and "threat" were significant. Consequently, there is insufficient evidence to conclude whether or not this moderator effect of threat on acculturative preferences is stronger for the public sphere than it is for the private sphere. These results suggest that the moderating effect of perceived threat on people's preferences for migrants who adopt the host culture is similar in both the public and private spheres.

\section{General discussion}

France's "republican integration model" is sometimes considered as assimilationist because migrants in France are expected to adopt the host culture and to abandon their original culture (Guimond, 2010). Nevertheless, despite the strong injunction to adopt the host culture, the French model does not totally exclude some conservation of the original culture, as migrants can preserve aspects of their original culture in the private sphere, over which the State does not exercise direct control. In the light of the French integration model, the present research was designed to examine the influence of host culture adoption and original culture conservation in the private sphere (in the present study, at home) and the public sphere (in the present study, at work) on the host population's judgments of migrants. We expected the French integration model to constitute a benchmark for French people. Our studies show that the situation is not as simple as that. The following discussion outlines the three main contributions made by our research. 
First, our results suggest that the host population's perceptions are influenced by the behaviors adopted by migrants in both the private and public spheres, and by the type of judgment being made, as the effects we found differed according to the dependent variable being examined (affective, normative, and perception of integration into French society). First, we predicted that participants would judge targets who adopt the host culture in public as being more likeable, better models of what is expected (prescriptive norm), and more integrated into French society than targets who conserve their original culture in public. Our results support this hypothesis only for the measure of integration into French society. We also predicted that, of migrants who conserve their original culture in public, participants would prefer those who adopt the host culture in private to those who conserve their original culture in both the private and public spheres. This hypothesis was supported by the results of both the pilot study and the main study in the case of the perception of integration, by the results of the main study and partly supported by the results of the pilot study in the case of the prescriptive norm, and partly supported by the results of both studies in the case of the affective measure. Taken together, these results suggest that the French integration model influenced our participants' perceptions of how well migrant populations are integrated, but at the same time, that this model has a weaker influence on their acculturation preferences or their acculturation expectations. This suggests that behaviors in the private and public spheres have different effects on judgments of migrants depending on the register of the judgment being made. It may be that the French integration model guided judgments of how well migrants are integrated into French society (the variable for which our results supported our hypotheses); nevertheless, in the case of judgments of likeability (affective measure) or judgments of what is ideally expected of a migrant (normative measure), their judgments may depend less on the French integration model. Thus, perceptions of migrants or people from migrant backgrounds may differ according to the type of judgment participants are asked to make, even when participants are judging the same target. For example, our results show that participants may say that a target (e.g., an assimilationist target) is well integrated into French society and a model of how they would like migrants to act, even if they do not like that target and find him hypocritical. This apparent contradiction revealed by some of our results indicates the inherent complexity of perceptions of migrant populations (Taillandier-Schmitt et al., 2012).

Our research's second main contribution derives from the results for the target's perceived honesty, which we measured in the main study. We found that targets who claimed to have adopted the host culture, whether in public or in private, were considered less honest than targets who admitted conserving their original culture. This suggests that participants made a de facto assumption that migrants conserve their original culture and are incapable of abandoning it. This result may throw light onto the phenomenon of the "ethnicization of social relations", which Costa-Lascoux and Hily (2001) defined as the use of ethnicity as a central criterion when decoding social interactions. It is, in fact, a culturalist drift in which excessive weight is given to the original culture when determining attitudes and behaviors. Considering migrants who claim to adopt the host culture to be less honest than migrants who admit to conserve their original culture may be another aspect of this phenomenon and may provide an interesting orientation for future research into perceptions of migrants. In the present study, targets who adopted the host culture at work and at home (assimilationist targets) were as less appreciated as targets who conserved their original culture at work and at home (separationist target). Previous studies have not reported such a rejection of assimilationist targets (Maisonneuve \& Testé, 2007; Van Oudenhoven et al., 1998). There are several possible explanations for this result. First, it may be that our participants preferred integration to assimilation because they perceived assimilationist migrants as a threat to the dominant group (Guimond, De Oliveira, Kamiesjki, \& Sidanius, 2010; Thomsen, Green, \& Sidanius, 2008). However, these authors obtained this result only for people with a high level of social dominance; therefore, it would be surprising if it applied to all the participants in our sample. Another possible explanation is suggested by our results for the "honesty" control measure. Because the only targets our participants considered honest were those who admitted to conserving their original culture either at work or at home, it may be that participants felt unable to say they liked someone they considered dishonest. This hypocrisy explanation for the rejection of assimilationist targets in our two studies may be related to an essentialist or culturalist drift affecting the host population's perceptions of migrants: because host populations believe migrants necessarily conserve at least part of their original culture, migrants who say they do not are seen as dishonest. This culturalist drift may also be a way for members of a host population to differentiate between the ingroup and the outgroup. As defined by social identity theory (Tajfel, 1978), permeability between groups predicts maintenance of positive self-esteem (Mummendey, Kessler, Klink, \& Mielke, 1999). Therefore, believing that migrants are incapable of totally "shedding" their original culture without being dishonest may be a way for members of the host population to maintain boundaries between groups and - as is the case for prejudices (Goodwin, Operario \& Fiske, 1998), meritocratic beliefs (McCoy \& Major, 2007), and social dominance (Levin et al., 2012) - a way for the dominant group to justify the system.

Our third contribution concerns the moderating effect of perceived threat. In line with previous research showing that perceived threat determines attitudes toward migrants (Florack et al., 2003) and is linked to perceptions of the host population's acculturative preferences (Lỏ pez-Rodríguez et al., 2014; Tip et al., 2012; Van Acker \& Vanbeselaere, 2011), our results show, as expected, that perceived threat moderates judgments in the public sphere and in the private sphere in the same way: compared with people who do not feel threatened by the presence of migrants, people who feel threatened are more likely to prefer a target who adopts the host culture than a target who conserves his own culture. We postulated that this effect would be stronger in the public sphere than in the private sphere. However, the interaction was not significant, which suggests that the moderating effect of threat is no stronger in the public sphere than it is in the private sphere. However, it may also have been a consequence of the measure we used to evaluate perceived threat. Both the realistic and symbolic dimensions of threat were present in the scale used, but did not emerge as two factors in the factorial analysis. Stephan and 
Stephan (1996), differentiated between "realistic threat", which they defined as a threat to the welfare of the ingroup (threats to its political or economic power and resources), and "symbolic threat", which refers to the ingroup's value system, belief system, or worldview. Several studies have shown that, together, realistic and symbolic threats predict negative attitudes toward immigrants (Stephan et al., 2005). The definitions of realistic and symbolic threats suggest they are likely to have different effects depending on the context.

The most important implication of our results is that studies of how migrants are judged must take into account the sphere in which a migrant's behavior takes place (Arends-Tóth \& Van de Vijver, 2004; Brown \& Zagefka, 2011; Navas et al., 2007). Previous research has not always done this (Florack et al., 2003; Maisonneuve \& Testé, 2007; Van Oudenhoven et al., 1998). Furthermore, distinguishing between the private and public spheres in scenario methods provides a new way of presenting "integration" strategies and encourages researchers to reflect on what is meant by the notion of integration. Classically, integration is considered as the syncretic conservation of the original culture and adoption of the host culture in all spheres, both private and public (Maisonneuve \& Testé, 2007; Van Oudenhoven et al., 1998). However, integration can also be defined as adopting the host culture in private and conserving the original culture in public (public assimilation), or adopting the host culture in public and conserving the original culture in private (public separation). Consequently, our mixed strategies could be considered integrated strategies. The contrast analyses carried out for our main study suggests that our participants' perceptions of the mixed strategies differed from their perceptions of the assimilation and separatism strategies. This suggests that the mixed targets were perceived as "integrated" targets but their form of integration was different to the integration encompassed by the bi-dimensional model. In fact, this form of integration is more in line with the alternation model, which was drawn up by Lafromboise, Coleman, \& Gerton (1993) as a second-culture acquisition model which "assumes that it is possible for an individual to know and understand two different cultures. It also supposes that an individual can alter his or her behavior to fit a particular social context." (p. 399). As Navas et al. (2007) suggested, "the concept of integration, in the sense of "aquire and maintain", participating while remaining as they are, may take different forms" ( $\mathrm{p} 83$ ). Undoubtedly, integration can take several different forms and it may be that the mixed strategies we proposed correspond better to the acculturation patterns of some migrants (Arends-Tóth \& Van de Vijver, 2004) and that the integration strategies of the bi-dimensional model correspond better to the acculturation patterns of other migrants. Our results show that migrants who adopt mixed acculturation strategies are perceived as behaving inconsistently but their behavior is considered more credible than that of migrants who adopt either conservation of their original culture or adoption of host culture strategies in both spheres of life. Moreover, mixed-strategy migrants are preferred, considered more integrated, and seen as a model to follow. The fact that mixed-strategy targets seem to be evaluated as positively as classic integrated targets perhaps suggests that mixed strategies are still viewed as a form of integration and therefore benefit from positive evaluations. These findings show that future research should systematically take into account the context in which behaviors are presented (Brown \& Zagefka, 2011; Navas et al., 2007) and more closely examine the concept of "integration", which can take various forms.

One limit of the present research concerns the way the private and public spheres were operationalized, as we considered only two settings, "strategy at home" and "strategy at work" (i.e., the most classic settings). However, the public sphere is not limited to the work setting and the private sphere is not limited to the home setting. Consequently, further studies are needed to determine whether our results also hold true for other private and public settings, for example, using a street setting to describe targets' behaviors in public. Furthermore, "strategy at work" and "strategy at home" are very general settings that include numerous dimensions. In the case of the home setting, targets' behaviors could be described in relation to areas such as culinary traditions, spoken language, religion, etc., thereby providing information about how behaviors in these sub-settings influence participants' judgments of targets. In fact, in the French integration model, citizenship and secularism (Kamiejski et al., 2012) are important factors that influence the host population's perceptions of migrants. Controlling for the perceived religiosity of the targets would have allowed us to determine whether or not conservation of the original culture was implicitly connected to the targets' religiosity. Many French people confuse being North African with being a strict Muslim (Liogier, 2012) and there is growing concern in France that the country's secular principles are being threatened by an increase in Islamization (extreme right-wing political propaganda). Our research did not include a measure of whether or not our North African targets who conserved their culture were perceived as being more religious, nor did we include a measure of perceived respect for France's secularist principles. Including the notion of secularism is crucial to future studies but this will be difficult to do, as the term is understood in numerous ways, many of which differ from its classic meaning in France's constitution. Consequently, adding a measure of perceptions of respect for France's secularist principles will require checking the representations and definitions participants call upon when judging targets.

A second limitation of our research is that both studies used single item measures for the "prescriptive norm" and the "perceived integration of the target into French society". In future research it would be better to use multi-item measures. A third limitation is that our results cannot be generalized. First, because of the size of our sample which is too small. Second, because our participants were all students following lifelong learning courses; therefore, they were not representative of the general population. Consequently, further work is needed to repeat our studies with larger groups of participants covering a representative cross-section of society. Nevertheless, due to their mean age and experience in the workplace, a population of lifelong learning students is more representative than a population of undergraduate students.

The present research focused on migrants' acculturation strategies in the private and public spheres in order to determine whether the French integration model guides French people's perceptions of migrants. We found that the influence of 
French's integration model depended on the type of judgments participants had to make (affective, normative, or degree of integration into French society). Another important variable that affected the host population's acculturative preferences was perceived threat. Because the media and, to some extent, politicians focus on the potential threats posed by migrants, rather than the possibility that migrants enrich the country, it is important to determine whether or not perceived threat significantly increases negative attitudes toward migrants.

\section{References}

Amadieu, J. F. (2008). The true and false solutions to the discriminations [Vraies et fausses solutions aux discriminations]. Formation emploi [En ligne] http://formationemploi.revues.org/1078

Arends-Tóth, J., \& Van de Vijver, F. J. R. (2003). Multiculturalism and acculturation: Views of Dutch and Turkish-Dutch. European Journal of Social Psychology, 33, 249-266. http://dx.doi.org/10.1002/ejsp.143

Arends-Tóth, J., \& Van de Vijver, F. J. R. (2004). Domains and dimensions in acculturation: Implicit theories of Turkish-Dutch. International Journal of Intercultural Relations, 28, 19-35. http://dx.doi.org/10.1016/j.ijintrel.2003.09.001

Barbier, M. (1995). (La laïcité) The secularism. Paris: L'Harmattan.

Barrette, G., Bourhis, R. Y., Personnaz, M., \& Personnaz, B. (2004). Acculturation orientations of French and North African undergraduates in Paris. International Journal of Intercultural Relations, 28, 415-438. http://dx.doi.org/10.1016/j.ijintrel.2004.08.003

Berry, J. W. (1980). Acculturation as varieties of adaptation. In A. M. Padilla (Ed.), Acculturation, theory, models and some new findings (pp. 9-25). Colorado: West View Pres Inc.

Berry, J. W. (2005). Acculturation: Living successfully in two cultures. International Journal of Intercultural Relations, 29, 697-712. http://dx.doi.org/10.106/j.ijintrel.2005.07.013

Berry, J. W. (2006). Mutual intercultural relations among immigrants and ethnocultural groups in Canada. International Journal of Intercultural Relations, 30, 719-734. http://dx.doi.org/10.106/j.ijintrel.2006.06.004

Berry, J. W., \& Kalin, R. (1995). Multicultural and ethnic attitudes in Canada: An overview of the 1991 national survey. Canadian Journal of Behavioural Science, 27, 301-320. http://dx.doi.org/10.1037/0008-400X.27.3.301

Berry, J. W., Kalin, R., \& Taylor, D. M. (1977). Multiculturalism and ethnic attitudes on Canada. Ottawa: Ministry of Supply and Services.

Bolzman, C. (2001). What right citizens? A typology of the models of integration of the migrants to the societies of residence. In C. Perregaux, T. Ogay, Y. Leanza, \& P. Dasen (Eds.), Intégrations et Migrations. Regards pluridisciplinaires (pp. 159-186). Paris: L'Harmattan.

Bourhis, R. Y., \& Bougie, E. (1998). Interactif acculturation model: An exploratoring study [Le modèle d'acculturation interactif: Une étude exploratoire]. Revue Québécoise de Psychologie, 19(3), 75-114.

Bourhis, R. Y., Moise, L. C., Perrault, S., \& Senecal, S. (1997). Towards an interactive acculturation model: A social psychological approach. International Journal of Psychology, 32, 369-386. http://dx.doi.org/10.1080/002075997400629

Brown, R., \& Zagefka, H. (2011). The dynamics of acculturation: An intergroup perspective. Advances in Experimental Psychology, 44, 130-176. http://dx.doi.org/10.1016/B978-0-12-385522-000003-2

Cohen, J., Cohen, P., West, S., \& Aiken, L. S. (2003). Applied Multiple Regression/correlation analysis for the behavioral sciences (third ed.). London: Lawrence Erlbaum Associates, Publishers.

Costa-Lascoux, J., \& Hily, M. A. (2001). The ethnicisation of the social link in the French suburbs [L'ethnicisation du lien social dans les banlieues françaises]. Revue Européenne de Migrations Internationales, 17, 123-138. http://dx.doi.org/10.3406/remi.2001.1781

Dambrun, M., \& Guimond, S. (2001). Relative deprivation theory and North-African hostility [La théorie de la privation relative et l'hostilité envers les Nord-Africains]. Revue Internationale de Psychologie Sociale, 14(1), 57-89.

Florack, A., Piontkowski, U., Rohmann, A., Balzer, T., \& Perzig, S. (2003). Perceived intergroup threat and attitudes of host community members towards immigrant acculturation. Journal of Social Psychology, 143(5), 633-648. http://dx.doi.org/10.1080/00224540309598468

Goodwin, S. A., Operario, D., \& Fiske, S. T. (1998). Situational power and interpersonal dominance facilitate bias and inequality. Journal of Social Issues, 54, 677-698. http://dx.doi.org/10.1111/j. 1540-4560.1998.tb01243.x

Guimond, S. (2010). (Psychologie sociale: Perspective multiculturelle) Social psychology: Multicultural perspective. Paris: Mardaga.

Guimond, S., De Oliveira, P., Kamiesjki, R., \& Sidanius, J. (2010). The trouble with assimilation: Social dominance and the emergence of hostility against immigrants. International Journal of Intercultural Relations, 34, 642-650. http://dx.doi.org/10.1016/j.ijintrel.2010.01.002

Kamiejski, R., Guimond, S., De Oliveira, P., Er-Rafiy, A., \& Brauer, M. (2012). The republican model of integration: Implications for intergroup psychology [Le modèle républicain d'intégration: Implications pour la psychologie des relations entre groupes]. L'Année Psychologique, 112, 49-83. http://dx.doi.org/10.4074/S0003503312001030

Lafromboise, T., Coleman, H. L., \& Gerton, J. (1993). Psychological impact of biculturalism: Evidence and theory. Psychological Bulletin, 114(3), 395-412.

Levin, S., Matthews, M., Guimond, S., Sidanius, J., Pratto, F., Kteily, N., et al. (2012). Assimilation, multiculturalism, and color blindness: Mediated and moderated relationships between social dominance orientation and prejudice. Journal of Experimental Social Psychology, 48, $207-212$. http://dx.doi.org/10.1016/j.jesp.2011.06.019

Liogier, R. (2012). (Mythe de l'islamisation. Essai sur une obsession collective) Myth of the Islamization. Attempt on a collective obsession. Paris: Seuil.

Lỏpez-Rodríguez, L., Zagefka, H., Navas, M., \& Cuadrado, I. (2014). Explaining majority members' acculturation preferences for minority members: A mediation model. International Journal of Intercultural Relations, 38, 36-46. http://dx.doi.org/10.1016/j.ijintrel.2013.07.001

Maisonneuve, C., \& Testé, B. (2007). Acculturation preferences of a host community: The effects of immigrant acculturation strategies on evaluations and impression formation. International Journal of Intercultural Relations, 31, 669-688. http://dx.doi.org/10.1016/j.ijintrel.2007.06.001

McCoy, S. K., \& Major, B. (2007). Priming meritocracy and the psychological justification of inequality. Journal of Experimental Social Psychology, 43, 341-351. http://dx.doi.org/10.1016/j.jesp.2006.04.009

Montreuil, A., \& Bourhis, R. Y. (2001). Majority acculturation orientations toward “valued" and “devalued" immigrants. Journal of Cross-Cultural Psychology, 32, 698-719. http://dx.doi.org/10.1177/0022022101032006004

Mummendey, A., Kessler, T., Klink, A., \& Mielke, R. (1999). Strategies to cope with negative social identity: Predictions by social identity and relative deprivation theory. Journal of Personality and Social Psychology, 76(2), 229-245. http://dx.doi.org/10.1037/0022-3514.76.2.229

Navas, M., García, M. C., Sánchez, J., Rojas, A. J., Pumares, P., \& Fernández, J. S. (2005). Relative acculturation extended model (RAEM): New contributions with regard to the study of acculturation. International Journal of Intercultural Relations, 29, 21-37. http://dx.doi.org/10.1016/j.ijintrel.2005.04.001

Navas, M., Rojas, A. J., García, M. C., \& Pumares, P. (2007). Acculturation strategies and attitudes according to the relative acculturation extended model (RAEM): The perspectives of natives versus immigrants. International Journal of Intercultural Relations, 31, 67-86. http://dx.doi.org/10.1016/j.ijintrel.2006.08.002

Sabatier, C., \& Berry, J. (1994). Immigration and acculturation. In R. Y. Bourhis, \& J. P. Leyens (Eds.), Stéréotypes, discriminations et relations intergroupes (pp. 261-291). Liège: Mardaga.

Sabatier, C., \& Boutry, V. (2006). Acculturation in francophone European societies. In D. L. Sam, \& J. W. Berry (Eds.), The Cambridge handbook of acculturation psychology (pp. 349-367). Cambridge: Cambridge University Press

Stephan, W. G., \& Stephan, C. W. (1996). Predicting prejudice. International Journal of Intercultural Relations, 20 , 409-426. http://dx.doi.org/10.1016/0147-1767(96)00026-0 
Stephan, W. G., Renfro, C. L., Esses, V. M., Stephan, C. W., \& Martin, T. (2005). The effects of feeling threatened on attitudes toward immigrants. International Journal of Intercultural Relations, 29(1), 1-19. http://dx.doi.org/10.1016/j.ijintrel.2005.04.011

Sorel-Sutter, M. (2011). (Immigration, intégration, le langage de vérité) Immigration, integration, the language of the truth. Editions Mille et une nuits.

Spire, A. (1999). From the foreigner to the immigrant [De l'étranger à l'immigré]. Actes de Recherche en Sciences Sociales, 129, 50-56. http://dx.doi.org/10.3406/arss.1999.3303

Taillandier-Schmitt, A., Maisonneuve, C., Dambrun, M., Loose, F., Gras, E., Tourret, I., et al. (2012). Social workers' Acculturative preferences in the context of professional insertion: Effects of personal attitudes and professional norms on professional practice [Préférences acculturatives des travailleurs sociaux dans le cadre de l'insertion professionnelle: Effets des opinions personnelles et de la norme professionnelle sur leurs pratiques]. Psychologie du Travail et des Organisations, 18(4), 308-327.

Tajfel, H. (1978). Differentiation between social groups. Studies in the social psychology of intergroup relations. London: Academic Press.

Testé, B., Maisonneuve, C., Assilamehou, Y., \& Perrin, S. (2012). What is an appropriate migrant? Impact of the adoption of meritocratic worldviews by potential newcomers on their perceived ability to integrate into a Western society. European Journal of Social Psychology, 42(2), 263-268. http://dx.doi.org/10.1002/ejsp.1844

Thomsen, L., Green, E. G. T., \& Sidanius, J. (2008). We will hunt them down: How social dominance orientation and right-wing authoritarianism fuel ethnic persecution of immigrants in fundamentally different ways. Journal of Experimental Social Psychology, 44, 1455-1464. http://dx.doi.org/10.1016/j.jesp.2008.06.011

Tip, L. K., Zagefka, H., Gonzales, R., Brown, R., Cinnirella, M., \& Na, X. (2012). Is support for multiculturalism threatened by threat. . itself? International Journal of Intercultural Relations, 36, 22-30. http://dx.doi.org/10.1016/j.ijintrel.2010.09.011

Tribalat, M. (2010). (Les yeux grands fermés. L'immigration en France) Eyes big closed. Immigration in France. Paris: Editions Denoël.

Van Acker, K., \& Vanbeselaere, N. (2011). Bringing together acculturation theory and intergroup contact theory: Predictors of Flemings' expectations 503 of Turks' acculturation behavior. International Journal of Intercultural Relations, 35, 334-345. http://dx.doi.org/10.1016/j.ijintrel.2010.06.004

Van Oudenhoven, J. P., Prins, K. S., \& Buunk, B. P. (1998). Attitudes of minority and majority members towards adaptation of immigrants. European Journal of Social Psychology, 28, 995-1013.

Van Oudenhoven, J. P., Ward, C., \& Masgoret, A. M. (2006). Patterns of relations between immigrants and host societies. International Journal of Intercultural Relations, 30, 637-651. http://dx.doi.org/10.1016/j.intrel.2006.09.001 